\title{
ARTICLE
}

\section{Crystallographic observation of 'induced fit' in a cryptophane host-guest model system}

\author{
Olena Taratula', P. Aru Hill', Najat S. Khan'1, Patrick J. Carroll' \& Ivan J. Dmochowski
}

Cryptophane-A, comprised of two cyclotriguaiacylenes joined by three ethylene linkers, is a prototypal organic host molecule that binds reversibly to neutral small molecules via London forces. Of note are trifunctionalized, water-soluble cryptophane-A derivatives, which exhibit exceptional affinity for xenon in aqueous solution. In this paper, we report high-resolution $X$-ray structures of cryptophane-A and trifunctionalized derivatives in crown-crown and crownsaddle conformations, as well as in complexes with water, methanol, xenon or chloroform. Cryptophane internal volume varied by more than $20 \%$ across this series, which exemplifies 'induced fit' in a model host-guest system. 
M olecular recognition is required for numerous processes in chemistry, biology and engineering. One prominent example is enzyme-substrate (E-S) complex formation, which, as Koshland ${ }^{1}$ proposed in 1958, may occur by 'induced fit'. Enzyme active sites undergo dynamic recognition upon substrate binding, with $\mathrm{E}$ and $\mathrm{S}$ rapidly adopting complementary conformations tailored for enzyme catalytic function. Such molecular recognition depends on the size and shape of the enzyme host and substrate guest molecules, as well as on conformational flexibilit ${ }^{2-5}$. The complexity of non-covalent host-guest interactions in natural supramolecular assemblies motivates our study of smaller synthetic systems.

Cryptophanes are widely investigated synthetic host molecules ${ }^{6}$ whose internal volume can be varied by changing the length or composition of the three alkane linkers joining two cyclotriguaiacylene (CTG) units. The linkers form three pores, which control guest entry, serving as size- and shape-selective filters. Numerous solution studies have characterized the reversible binding of cryptophane hosts to small molecules ${ }^{6}$. The internal volume of cryptophane-A with three ethylene linkers was reported previously as either $81.5 \AA^{3}$ (ref. 7) or $95 \AA^{3}$ (ref. 8), on the basis of modelling studies. The spherical molecules methane $\left(28 \AA^{3}\right)$, xenon $\left(42 \AA^{3}\right)$ and chloroform $\left(72 \AA^{3}\right)$ gain entry, and span the range of accessible volumes. Methane binds to cryptophane-A with a relatively large association constant compared with other host molecules, $K_{\mathrm{A}}=130 \mathrm{M}^{-1}$ at $298 \mathrm{~K}$ in $\mathrm{C}_{2} \mathrm{D}_{2} \mathrm{Cl}_{4}$ (ref. 7). Under these conditions, similar binding to crytophane-A occurs with chloroform, $K_{\mathrm{A}}=230 \mathrm{M}^{-1}$ (ref. 7), and by far the highest affinity has been measured for xenon, $K_{\mathrm{A}}=3,900 \mathrm{M}^{-1}$ (ref. 9). The preference for xenon has been a mystery: using the available chloroform-cryptophane-A structures ${ }^{10}$ as a template, the Xe atom is predicted to underfill the cavity.

To date, cryptophanes- $\mathrm{A}^{10}$ and $-\mathrm{E}^{11}$ have only been crystallized with chloroform, and cryptophanes- $\mathrm{C}$ and -D have been crystallized with dichloromethane ${ }^{12,13}$. Cavagnat et al..$^{10}$ obtained small crystals of the $\mathrm{CDCl}_{3}$-cryptophane-A complex in three different morphologies (rhombic, rod-like and polyhedral) and these were structurally determined by X-ray diffraction and studied by Raman microspectrometry. However, no small-molecule X-ray structure of a xenon-cryptophane complex has been reported. Providing some precedent are crystal structures of xenon bound to calixaren $\mathrm{e}^{14,15}$ and cucurbit[5] uril ${ }^{16}$ hosts. Also relevant are protein X-ray crystal structure determinations in which xenon was used as a heavy atom to improve phasing ${ }^{17}$. Finally, we reported a 1.7 -Å resolution macromolecular crystal structure of a xenon biosensor bound to carbonic anhydrase II, which indicated electron density corresponding to a single xenon atom bound within the cryptophane ${ }^{18}$.

There is growing interest in functionalized cryptophane-A derivatives based on the significant potential of hyperpolarized ${ }^{129} \mathrm{Xe}$ for biodetection and biomolecular imaging ${ }^{19,20}$. Recently, MS2 virus capsid decorated with 125 cryptophanes was detected at subpicomolar concentrations by hyperpolarized ${ }^{129} \mathrm{Xe}$ nuclear magnetic resonance (NMR) spectroscopy ${ }^{21}$. Using a tripropargyl-derivatized cryptophane-A, our laboratory synthesized cryptophane-benzenesulfonamide biosensors that produced ${ }^{129} \mathrm{Xe}$ NMR chemical shift differences of 3.0-7.5 p.p.m. on binding carbonic anhydrase isozymes $^{22}$. We also generated peptide-modified cryptophane that was delivered to human cancer cell lines ${ }^{23}$.

A triacetate-functionalized cryptophane- $\mathrm{A}^{24}$ shows the highest xenon affinity of any host molecule, $K_{\mathrm{A}}=3.3 \times 10^{4} \mathrm{M}^{-1}$ at $293 \mathrm{~K}$ in buffer. The higher affinity of xenon for cryptophane in water results from entropic ('hydrophobic') effects that likely involve desolvation of xenon clathrates upon complexation. We have also hypothesized that cryptophane-A adopts a more compact shape in water, which should increase favourable van der Waals contacts with xenon ${ }^{24}$. Although conformational flexibility of the three alkoxy linkers has been observed in solution previously ${ }^{9,25,26}$, until now, there has been

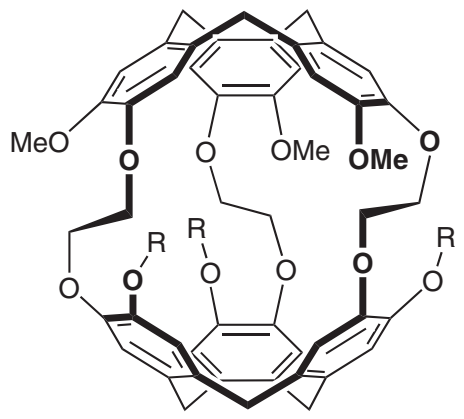

$\mathbf{R}=$ OMe Cryptophane-A

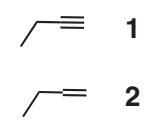

Figure 1 | Cryptophane hosts used in this study. Cryptophane-A, tripropargyl (1) and triallyl (2) derivatives are shown as single enantiomers.

little evidence of volume changes in the 'open' crown-crown (CC) conformation of cryptophane- $\mathrm{A}$, and this is often considered as a fixed cavity.

Synthetic host binding sites have also been investigated with macrocyclic compounds such as cyclodextrins, crown ethers and cyclophanes ${ }^{27,28}$. Cyclodextrin studies suggest that the guest inclusion process is influenced by hydrophobic interactions, as well as by the shape and size of the guest ${ }^{28}$. Recently, crystallographic studies revealed changes in $\beta$-cyclodextrin conformation upon quinine encapsulation ${ }^{29}$.

Here, we report X-ray crystal structures showing analogous induced fit in a cryptophane host-guest model system. Unlike many small-molecule host systems that have been characterized crystallographically to date, cryptophanes contain a three-dimensional hydrophobic cavity, which approximates many enzyme active sites. Because of minimal electrostatic interactions in these host-guest complexes, cryptophane binding is driven by favourable London forces. Cryptophane-A, tripropargyl (1) and triallyl (2) derivatives (Fig. 1) were crystallized with various encapsulated hydrophobic guests, including xenon. Notably, the cryptophane internal volume increased by more than $20 \%$ as the guest volume increased from methanol to chloroform.

\section{Results}

Crystallization parameters. For crystallization of cryptophane-guest complexes, it was necessary to avoid solvents that compete for binding inside the cryptophane cavity. Fluorobenzene is a sterically bulky solvent that adequately solubilizes $\mathbf{1}$ and $\mathbf{2}$ to allow for crystal growth by vapour diffusion of diethyl ether or $n$-pentane. Cryptophane-A, 1 and $\mathbf{2}$ as racemic mixtures cocrystallized with xenon exhibited the CC conformation (Fig. 2a,c,e). Moreover, in the absence of suitable guests, the crystal structure of $\mathbf{1}$ revealed cryptophane in the CC conformation (Fig. 2d), in agreement with solution ${ }^{1} \mathrm{H}$ NMR data. Either without guests or with xenon, 1 crystallized in the triclinic space group P $\overline{1}$. The chirality of cryptophane-A arises from the anti relationship of the methoxy groups relative to the ethylene oxide bridges, as was also observed in previous cryptophane X-ray structures ${ }^{6,11}$.

Complexed and collapsed cryptophane structures. Crystal structures of cryptophane-A, $\mathbf{1}$ and $\mathbf{2}$ with xenon as guest (Fig. 2a,c,e) revealed, as expected, one Xe atom centrally located within the cryptophane cavity. From the calculated Xe-carbon atom distances at the phenyl rings in the Xe- 2 complex (range $=4.03-4.73 \AA$, average $=4.31 \AA$, Supplementary Table S1), it is evident that Xe is positioned near the optimal distance from CTG units: van der Waals 


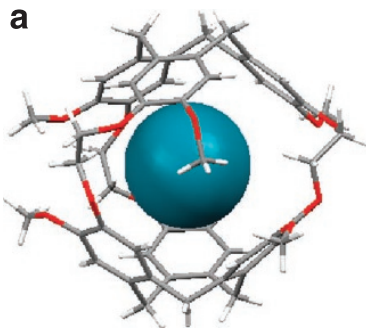

C
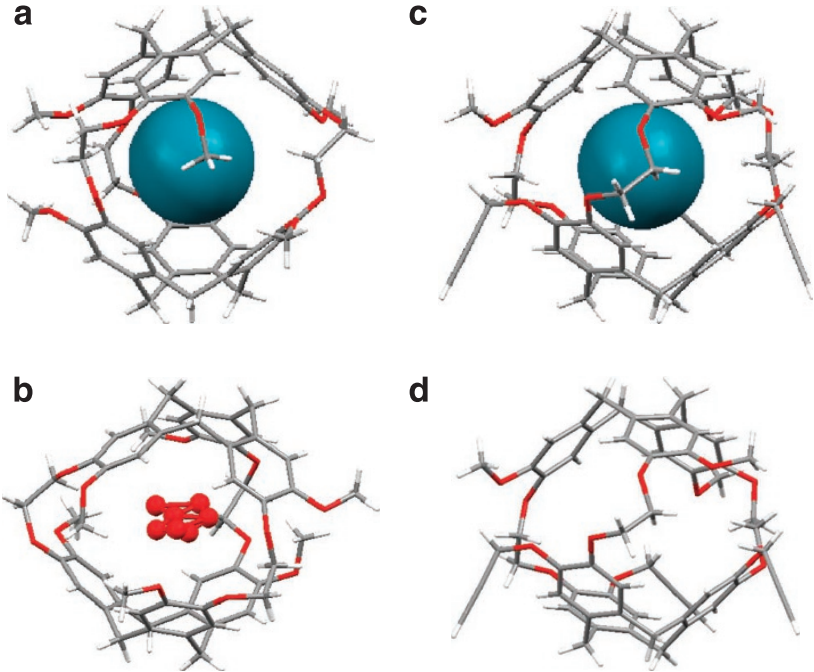

d

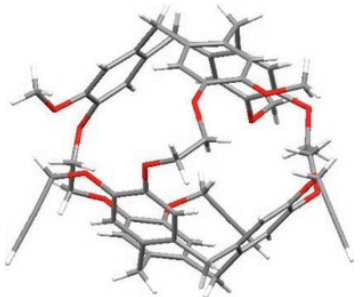

e

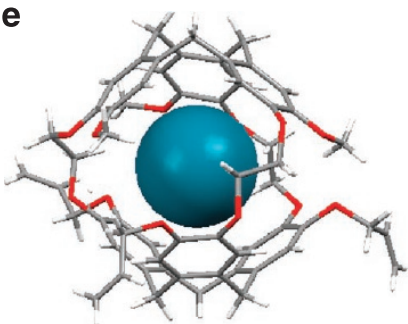

$\mathbf{f}$

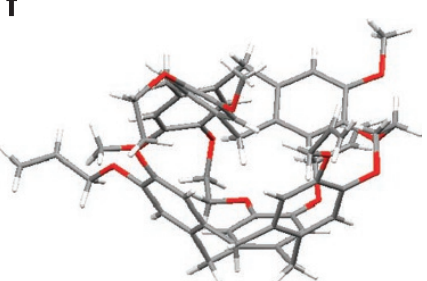

Figure $\mathbf{2}$ | X-ray crystal structures of cryptophanes and inclusion complexes in side view. (a) Cryptophane-A with Xe, and $\mathbf{b}$, with water, oxygen shaded red; both in CC conformation. (c) Tripropargyl cryptophane (1), with Xe, and d, partially occupied; both in CC conformation. (e) Triallyl cryptophane (2), with $\mathrm{Xe}$, in CC conformation. Xe atom is shaded blue; and $\mathbf{f}$, collapsed, in CS conformation.

interaction distance for Xe and phenyl carbon is $3.86 \AA^{30}$ (where steric repulsion and favourable induced dipolar interaction are balanced).

We also report the first X-ray structure of cryptophane-A cocrystallized with water (Fig. 2b). The cryptophane-water structure was found to encapsulate one water molecule containing partial electron density from the water oxygen atom occupying seven different positions within the cavity. This disordered arrangement is consistent with 'bound' water not being observed at room temperature by solution ${ }^{1} \mathrm{H}$ NMR spectroscopy. It is relevant that molecular dynamics simulations previously identified an average of only $\sim 2.1$ water molecules within the somewhat larger cryptophane-E cavity ${ }^{31}$.

A crystal structure was obtained for 2 in a 'collapsed' crownsaddle (CS) conformation (Fig. 2f). CS-2 crystallized in the monoclinic space group $\mathrm{P} 2 / \mathrm{n}$ with two of the allyl groups observed in two different possible orientations. This experimentally determined structure appears to agree with the one calculated previously by Huber et al. ${ }^{32}$ The $C_{1}$ symmetric structure of CS-2 (Fig. 2f) shows the bridging methylene pointing into the cavity. Although CS-2 is the first crystal structure of the CS conformer of a cryptophaneA derivative, a related CS conformer of a cryptophane possessing $m$-xylyl linkers between the CTG units was previously studied by solution ${ }^{1} \mathrm{H}$ NMR spectroscopy and single crystal X-ray diffraction by Mough et al. ${ }^{33}$. Although it is expected that CS-2 is destabilized relative to the crown form of CTG by $3-4 \mathrm{kcal} \mathrm{mol}^{-1}$ (ref. 34), we conclude that crystal packing forces on 2 in the absence of guest can promote the CS conformation in the solid state. Interestingly, the allyl-substituted CTG of CS-2 retained its crown conformation, whereas the methoxy-substituted CTG assumed the saddle conformation. The crystal structure of CS-2 suggests that tri-substituted cryptophane-A derivatives can access this energetically less stable, non-xenon-binding conformer in solution as well, as we previously proposed for water-soluble cryptophane-A derivatives ${ }^{24}$ and as observed for hexa-acid cryptophane-A derivatives ${ }^{32}$.

Cryptophane host-guest volume calculations. Mecozzi and Rebek surveyed many host-guest interactions mediated by London forces and determined empirically that optimal binding occurs when the guest occupies $55 \pm 9 \%$ of the host interior volume ${ }^{8}$. In cryptophane host systems in organic solution and water, it has been established that the lengths and conformations of the alkoxy linkers connecting the two CTG units regulate the size of the internal cavity, which in turn affects the Xe binding constant ${ }^{32,35}$. For example, a smaller cryptophane-1,1,1 was synthesized ${ }^{36}$ with an approximate internal volume of $81 \AA^{3}$, making the volume ratio of the xenon guest to the host cavity equal to $\sim 0.52$. In this case, the xenon association constant, $K_{\mathrm{A}}=10,000 \mathrm{M}^{-1}$ at $298 \mathrm{~K}$ in $\left(\mathrm{CDCl}_{2}\right)_{2}$ (ref. 36), was determined to be almost threefold higher than that for cryptophane-A. Xenon binding may be nearly optimized for the cavity in cryptophane-1,1,1, although, without crystal structures, the Xe packing fraction can only be approximated for this host-guest complex.

To investigate systematically the manner in which the size of the guest molecule influences the cryptophane cavity, we determined structures of the readily crystallized triallyl cryptophane $\mathbf{2}$ with $\mathrm{MeOH}, \mathrm{Xe}$ and $\mathrm{CDCl}_{3}$. The internal volumes of $\mathbf{2}$ in these complexes were calculated with Swiss Pdb Viewer ${ }^{37}$ after deleting the encapsulated guest from the pdb files (Table 1). Although crystal packing forces undoubtedly have an effect on the observed molecular conformations, the fact that $\mathbf{2}$-guest complexes all crystallized in the monoclinic space group $\mathrm{P} 2{ }_{1} / \mathrm{c}$ facilitates comparisons between the different structures. In contrast, we were unable to find an internal void volume for CS-2, as the collapsed cavity was too small to accommodate a $1.4 \AA$ diameter probe.

As can be seen in Table 1, the internal volume of 2 increased by a remarkable $21 \%$, from 84 to $102 \AA^{3}$ as the size of the guest molecule increased from $\mathrm{MeOH}$ to $\mathrm{CDCl}_{3}$. The guest packing coefficient (defined as guest volume divided by host internal volume) increased even more dramatically across this series, $0.39 \rightarrow 0.73$. Importantly, cryptophane-A, $\mathbf{1}$ and $\mathbf{2}$-with different peripheral substituentsexhibited very similar cavity volumes for the same guest. Thus, it was possible to compare crystallographic data for these three cryptophane hosts. Xenon bound to cryptophane-A, 1 and $\mathbf{2}$ gave similar cavity volumes $\left(85-89 \AA^{3}\right)$ and packing coefficients $(0.47-0.49$, Table 1$)$. Cryptophane-A adopts an intermediate-volume conformation for Xe, which brings the packing fraction close to Rebek's empirically determined value. This presumably achieves a favourable balance of enthalpic and entropic forces and contributes to high Xe affinity. Notably, an overlay of the CC-1 and 1-Xe structures showed virtually no change induced by Xe encapsulation (see Supplementary Fig. S1). This provides further evidence that the cryptophane-A structure is nearly optimal for Xe binding.

Figure 3 illustrates how xenon is sandwiched by three pairs of phenyl rings belonging to the two opposing CTG units. As noted previously, many of the phenyl carbon atoms nearly achieve van der 
Table 1 | Internal volumes of host molecule cryptophane-A and derivatives 1 and 2, guest volumes, and packing coefficients.

\begin{tabular}{|c|c|c|c|c|}
\hline Guest & Host & Internal volume $\left(\AA^{3}\right)^{\star}$ & Guest volume $\left(\AA^{3}\right)$ & Packing coefficient $i$ \\
\hline 'Collapsed' & CS-2 & - & - & - \\
\hline Partial occupancy & $\mathrm{CC}-1+$ & 87 & - & - \\
\hline $\mathrm{H}_{2} \mathrm{O}$ & Crypt-A & 88 & 18 & $0.20 s$ \\
\hline $\mathrm{MeOH}$ & 2 & 84 & 33 & 0.39 \\
\hline \multirow[t]{4}{*}{$\mathrm{Xe}$} & 2 (conf. 1) $\|$ & 89 & 42 & 0.47 \\
\hline & 2 (conf. 2) $\|$ & 87 & 42 & 0.48 \\
\hline & 1 & 85 & 42 & 0.49 \\
\hline & Crypt-A & 89 & 42 & 0.47 \\
\hline \multirow[t]{2}{*}{$\mathrm{CDCl}_{3}$} & 2 (conf. 1) $\|$ & 102 & 72 & 0.71 \\
\hline & 2 (conf. 2) $\|$ & 98 & 72 & 0.73 \\
\hline $\begin{array}{l}\text { * Internal volumes were c } \\
\uparrow \text { Packing coefficient is gu } \\
\text { †Diffuse electron density } \\
\text { §This value is based on o } \\
\text { \|Some crystal structures }\end{array}$ & $\begin{array}{l}\text { Deep View/Sw } \\
\text { led by host inte } \\
\text { sside the CC-1 } \\
\text { molecule, wher } \\
\text { mers, which di }\end{array}$ & $\begin{array}{l}\text { d to an encapsulated guest bu } \\
\text { responding to water in seven } \\
\text { s of the side chains and in thei }\end{array}$ & $\begin{array}{l}\text { ue to trace water. } \\
\text { sitions was observed. } \\
\text { d internal volumes. }\end{array}$ & \\
\hline
\end{tabular}

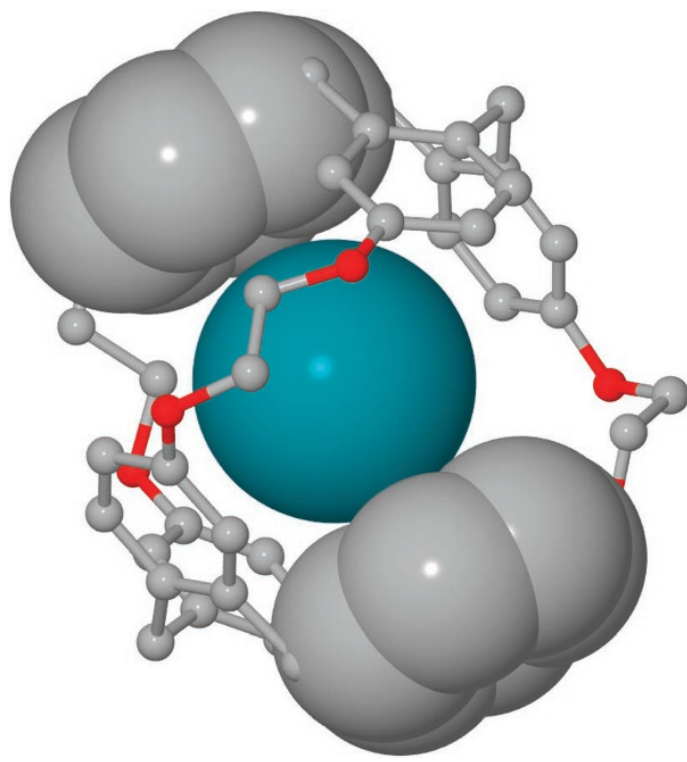

Figure $\mathbf{3}$ | Zoomed view of the Xe-2 complex. This highlights van der Waals interactions between phenyl carbon atoms and xenon. Hydrogen atoms and side chains were removed for clarity. Only Xe atom and two phenyl groups from opposing CTG units are depicted with van der Waals radii.

Waals contact with $\mathrm{Xe}$. In contrast, the $\mathrm{Xe}-\mathrm{C}$ distances at the linkers are larger (range $=4.54-5.41 \AA$, average $=5.00 \AA$, Supplementary Table S1), when the van der Waals interaction distance for Xe and tetrahedral carbon is $4.16 \AA^{30}$. The flexible ethylene linkers reside farther away (Fig. 3 ) and interact more weakly with Xe, on average, but provide the CTG units with mobility to accommodate Xe in the cavity and optimize Xe-phenyl interactions.

Unlike xenon, $\mathrm{MeOH}$ clearly underfills the cryptophane cavity, with packing coefficient 0.39 (Table 1 ). Importantly, $\mathrm{MeOH}$ is very similar in size to methane, which is the smallest molecule the binding of which has been characterized for cryptophane- $\mathrm{A}^{7}$. On the basis of the low packing coefficient for this smallest guest, it appears to be energetically unfavourable for the cavity to shrink to less than $84 \AA^{3}$, as found in the $\mathrm{MeOH}$ structure. Crystal packing forces may also have a role in stabilizing the conformation of cryptophane in the $\mathrm{MeOH}$ structure.

The other exception to Rebek's '55\% solution'8 involves $\mathrm{CDCl}_{3}$, which at $72 \AA^{3}$ has the potential to fill the cryptophane cavity almost entirely. In fact, the cryptophane volume expanded to $102 \AA^{3}$ in the
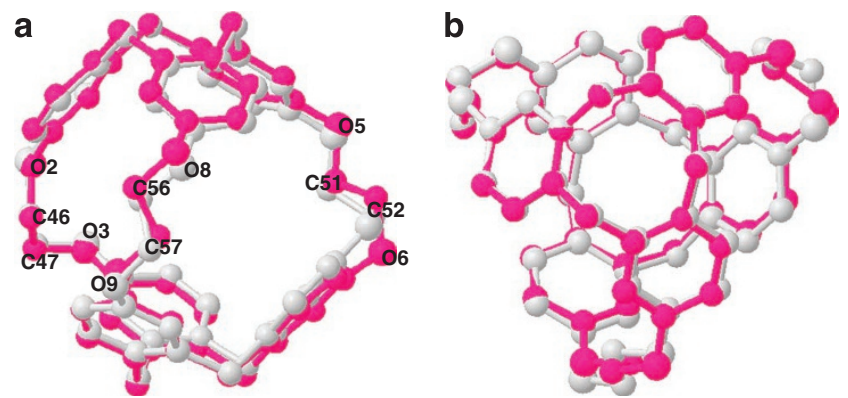

Figure 4 | Side (a) and (b) top views of two superimposed crystal structures of triallyl cryptophane (2). $\mathbf{2}$ is shown encapsulating $\mathrm{MeOH}$ (grey) and $\mathrm{CDCl}_{3}$ (pink). Guests, hydrogens and side chains were removed for easier viewing.

2- $\mathrm{CDCl}_{3}$ structure, which reduced the entropic penalty but still yielded a large packing coefficient of 0.73 .

Cavagnat et al. ${ }^{10}$ determined that the chlorine atoms of chloroform occupy the central equatorial plane of cryptophane-A, and the $\mathrm{C}-\mathrm{H}$ bond is collinear with the $\mathrm{C}_{3}$ axis of the cryptophane molecule. A similar orientation of chlorine atoms was observed for the larger cryptophane-E host, in which the $\mathrm{C}-\mathrm{H}$ bond points either up or down along the pseudo $C_{3}$ axis, towards one of the CTG units ${ }^{11}$. For 2- $\mathrm{CDCl}_{3}$, we observed a similar orientation of the guest, with the deuterium directed to the centre of the allyl-modified CTG (see Supplementary Fig. S2). We reviewed the previously deposited chloroform-bound cryptophane-A structures in the three different crystal morphologies (rhombic, rod-like and polyhedral; CSD ref. codes IYEVEN, IYETUB and IYEVAJ $)^{10}$, but were unable to reliably calculate the volume of cryptophane-A, or identify meaningful conformational differences between these structures, because of a high degree of molecular disorder. To a coarse approximation, similarly large cavities were identified for the three different structures, with expanded volumes consistent with the $2-\mathrm{CDCl}_{3}$ structure.

Cryptophane conformational changes seen for induced fit. By overlaying the computed cavities for $2-\mathrm{MeOH}$ and $2-\mathrm{CDCl}_{3}$, it is evident that $\mathrm{CDCl}_{3}$ binding induces the cavity to expand from the centre of mass (Supplementary Fig. S3). The crystallographic data indicate that the cavity can adapt to fit the encapsulated guest molecule. How does this 'induced fit' occur?

Overlaid structures of 2, complexed with $\mathrm{MeOH}$ and $\mathrm{CDCl}_{3}$ (Fig. 4), provide clear indication that the internal volume of cryptophane-A is controlled by the three $\mathrm{O}-\mathrm{CH}_{2}-\mathrm{CH}_{2}-\mathrm{O}$ linkers connecting the CTG units. We used CrystMol 2.1 (ref. 38) to superimpose 
the carbon backbone structures of 2 with bound $\mathrm{MeOH}$ and $\mathrm{CDCl}_{3}$, as these guests produced the largest difference in host cavity volume (Table 1). The superimposed cryptophane structures show the smaller 2-MeOH structure (Fig. 4, grey carbon backbone) residing mostly inside the pink carbon backbone representing $2-\mathrm{CDCl}_{3}$. The structures can be aligned such that one of the ethylenedioxy linkers (labelled $\mathrm{O}_{(2)}-\mathrm{C}_{(46)} \mathrm{H}_{2}-\mathrm{C}_{(47)} \mathrm{H}_{2}-\mathrm{O}_{(3)}$ ) is almost unchanged. However, linker $\mathrm{O}_{(8)}-\mathrm{C}_{(56)} \mathrm{H}_{2}-\mathrm{C}_{(57)} \mathrm{H}_{2}-\mathrm{O}_{(9)}$ in the $2-\mathrm{CDCl}_{3}$ complex is partly expanded such that the $\mathrm{O}_{(8)}-\mathrm{O}_{(8)}$ and $\mathrm{C}_{(56)}-\mathrm{C}_{(56)}$ distances between the two structures differ by 0.56 and $0.65 \AA$, respectively. An even more pronounced change is seen for the third linker, $\left(\mathrm{O}_{(5)}-\mathrm{C}_{(51)} \mathrm{H}_{2}-\mathrm{C}_{(52)} \mathrm{H}_{2}\right.$ $\left.\mathrm{O}_{(6)}\right) ; \mathrm{O}_{(6)}-\mathrm{O}_{(6)}$ and $\mathrm{C}_{(52)}-\mathrm{C}_{(52)}$ distances differ by 0.89 and $1.06 \AA$ (Fig. 4, Supplementary Table S2). These data show that cryptophaneA can expand both horizontally and vertically upon binding the larger chloroform guest, moving the CTG units farther apart by as much as $0.4 \AA$.

In this crystallographic study, we also examined geometrical parameters of the ethylenedioxy linkers that changed during the guest-binding process. In contrast with previous solution spectroscopic studies ${ }^{9,25,26}$, ethylenedioxy linkers exhibited mixed anti and gauche conformations in the solid state. This determination was based on measured dihedral angles $(\Theta 1, \Theta 2, \Theta 3)$ for all three linkers from the perspective of the 'north' pole of the cryptophane, as defined by CTG with allyl substituents (Fig. 5). By increasing the guest volume from $\mathrm{MeOH}$ to $\mathrm{CDCl}_{3}$, the most dramatic change was observed for the linker labelled $\mathrm{O}_{(5)}-\mathrm{C}_{(51)} \mathrm{H}_{2}-\mathrm{C}_{(52)} \mathrm{H}_{2}-\mathrm{O}_{(6)}$ : the conformation changed from gauche to anti with the dihedral angle decreasing from $74.5^{\circ}$ to $-171.7^{\circ}$ (Table 2). Such linker transformations allow the increased vertical distance between CTG units observed for chloroform encapsulation (Supplementary Table S2), and also allow the cavity to expand horizontally upon binding<smiles>OC1OC2CC3OC2CC13</smiles>

anti<smiles>OC1C2CC3CC1OC3O2</smiles>

gauche

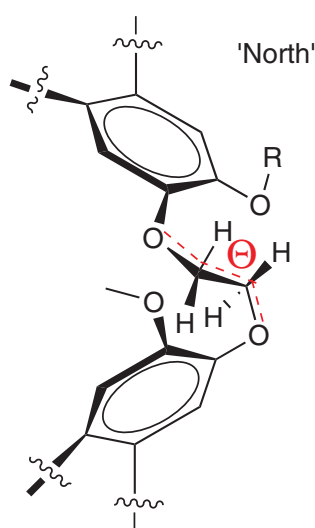

Figure 5 | Ethylenedioxy linker of cryptophane-A. Both anti and gauche conformations are observed in all crystal structures of cryptophane hostguest complexes. this largest guest. The superimposition of cryptophane structures with different sized guests, in addition to calculated internal volumes and dihedral angles, indicate how cryptophane-A can accommodate guests of varied shape and size.

\section{Discussion}

Previously unstudied in the solid state, xenon-cryptophane association was shown earlier in solution studies to depend on many factors, including the size, shape, rigidity, accessibility and polarity of the cage, as well as solvent. In particular, the Xe-cryptophane-A binding interaction has been studied by several experimental techniques including isothermal titration calorimetry, electronic circular dichroism, vibrational circular dichroism (VCD), NMR, as well as infrared and fluorescence spectroscopies ${ }^{9,25,35,39-42}$. ${ }^{129} \mathrm{Xe}$ NMR chemical shift varies considerably in different cryptophane environments and solvent ${ }^{19,20}$, but requires further benchmarking before it can be used to illuminate Xe-cryptophane interactions. Spin polarization-induced nuclear Overhauser effect measurements can estimate xenon-proton internuclear distances for cryptophane in solution, on the basis of site-selective ${ }^{1} \mathrm{H}$ NMR enhancements from hyperpolarized ${ }^{129} \mathrm{Xe}$ (ref. 40); however, crystal structures should allow more accurate distance assignments.

Interestingly, the packing fraction of 0.73 determined for the 2- $\mathrm{CDCl}_{3}$ structure is consistent with the closest packing arrangement of uniform spheres, in which the fraction of space occupied by the spheres is 0.74 . A packing fraction of 0.73 suggests a nearly maximal internal volume for the cryptophane, particularly as no guest larger than chloroform has been reported to be encapsulated by cryptophane- $\mathrm{A}$ in solution. The expanded $\left(102 \AA^{3}\right)$ cavity volume observed for 2 - $\mathrm{CDCl}_{3}$ stands in contrast to the $82 \AA^{3}$ volume reported for the previous cryptophane-A-chloroform crystal structures $^{10}$, although this value appears to be approximated. The calculation of crystallographically determined molecular cavity volumes and the observed expansion of the cryptophane cage upon binding larger guests are useful for addressing important issues first raised by Collet and co-workers ${ }^{7}$ about the atomic densities and pressures that can be achieved in non-covalent cryptophane-guest complexes.

Previous solution studies showed that encapsulation of guests by cryptophane-A can induce conformational changes in ethylenedioxy linkers ${ }^{9,25,26,43}$. For example, chiroptical changes observed by VCD and electronic circular dichroism indicated that cryptophane-A ethylenedioxy linkers adopt an all-anti conformation upon encapsulation of bulky guests such as chloroform ${ }^{25}$. Moreover, experimental and simulated VCD spectra suggested a preferential gauche linker conformation when cryptophane-A is without any guests or bound to smaller guests ${ }^{26}$. ${ }^{1} \mathrm{H}$ NMR spectroscopy also indicated that $\mathrm{OCH}_{2} \mathrm{CH}_{2} \mathrm{O}$ linkers adopt a gauche conformation in the $\mathrm{Xe}$-cryptophane-A complex'. Contrary to these solution studies, we observed a mixture of both gauche and anti linker conformations in all cryptophane crystal structures, except for the all-gauche CS-2 collapsed structure. In the CC cryptophane structures, the linker

Table 2 | Crystallographically determined dihedral angles and conformational assignments of the $-\mathbf{O}-\mathrm{CH}_{2}-\mathrm{CH}_{2}-\mathrm{O}-$ linkers in 1 and 2.

\begin{tabular}{|c|c|c|c|c|}
\hline Guest & Host & $\Theta 1\left(^{\circ}\right)^{\star} /$ Conf. & $\Theta 2\left(^{\circ}\right)^{\star} /$ Conf. & $\Theta 3\left(^{\circ}\right)^{\star} /$ Conf. \\
\hline 'Collapsed' & CS-2 & 63.9/gauche & -87.7/gauche & -63.9/gauche \\
\hline Partial occupancy & CC-1 & 72.3/gauche & -165.3 /anti & 73.8/gauche \\
\hline $\mathrm{MeOH}$ & 2 & 77.4/gauche & 171.9/anti & 74.5/gauche \\
\hline \multirow{2}{*}{$\mathrm{Xe}$} & $2(\operatorname{conf} .2)^{\star}$ & 73.5/gauche & $-166.9 /$ anti & 70.7/gauche \\
\hline & 1 & 71.9/gauche & $-164.8 /$ anti & 73.2/gauche \\
\hline $\mathrm{CDCl}_{3}$ & $2(\operatorname{conf} .1)^{\star}$ & 75.3/gauche & -174.0/anti & $-171.7 /$ anti \\
\hline
\end{tabular}

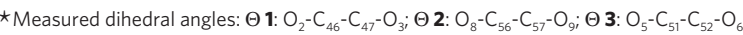


conformations were not correlated with the presence of guests or guest volume.

This crystallographic study improves understanding of the prototypal cryptophane host and related cavity-containing organic host molecules, which are often assumed to adopt conformations with a narrow range of cavity volumes. This is also relevant for xenon biosensing applications, as manipulating the cryptophane cavity can produce significant changes in xenon affinity and ${ }^{129} \mathrm{Xe}$ NMR chemical shift. Finally, London forces are important to all molecular interactions in Nature, but are often difficult to elucidate because of their small magnitude (typically $<2 \mathrm{~kJ} \mathrm{~mol}^{-1}$ ) and the predominance of electrostatic interactions. The study of model host-guest systems using X-ray crystallography is useful for elucidating the role of weak interactions in molecular recognition.

In conclusion, we report the first crystal structures of cryptophane-A and derivatives without guests in CC and CS conformations, as well as in complexes with chloroform, xenon, methanol and water. A crystallographic analysis revealed that these cryptophanes can undergo 'induced fit' to improve guest binding interactions; the internal volume of the host varied by more than $20 \%$ to accommodate a wide range of hydrophobic guests. The ethylenedioxy linkers of cryptophane-A confer conformational flexibility that allows both vertical and lateral changes to the cavity, for adaptation to guests ranging in volume from $\mathrm{MeOH}\left(33 \AA^{3}\right)$ to $\mathrm{CDCl}_{3}\left(72 \AA^{3}\right)$. Of particular interest are xenon-bound structures, which identify nearly optimized van der Waals interactions between xenon and the CTG phenyl moieties.

\section{Methods}

Synthesis. Cryptophane-A was obtained by seven-step synthesis with an overall yield of $4.4 \%$ (ref. 44). Tripropargyl (1) and triallyl (2) cryptophane derivatives were synthesized according to published procedures in 9 and 10 steps with an overall yield of 4.9 and $2.9 \%$, respectively $y^{24,45}$.

Crystal growth. Cryptophane-A and compounds $\mathbf{1}$ and $\mathbf{2}$ were each crystallized as a racemic mixture, with guests $\left(\mathrm{H}_{2} \mathrm{O}, \mathrm{MeOH}, \mathrm{Xe}, \mathrm{CDCl}_{3}\right)$ or without guests, by slow evaporation or by vapour diffusion of diethyl ether, $n$-pentane or hexanes into different solvents. Single crystals were grown in $\mathrm{CDCl}_{3}$ by slow evaporation, whereas crystals of $\mathrm{MeOH}$ included within the cryptophane cavity were grown by vapour diffusion. Fluorobenzene was chosen as solvent to grow cryptophane-xenon crystals as it is too large to occupy the cavity of the cryptophane and exhibits enough solubility towards cryptophanes to allow for the growth of a single crystal by vapour diffusion technique. The fluorobenzene solution of cryptophane was degassed with static vacuum and bubbled with Xe gas. The precipitating solvent (diethyl ether, $n$-pentane or hexanes) was also bubbled with Xe and the headspace of the vapour diffusion vial was purged with Xe before it was sealed. Single crystals of 'collapsed' CS-2 were obtained by means of dissolution in hot mesitylene, cooling to room temperature and subjecting to vapour diffusion conditions with $n$-pentane.

Crystal structure determination. X-ray intensity data were collected on a Rigaku AFC7 four-circle diffractometer equipped with a Mercury CCD area detector using graphite-monochromated Mo- $\mathrm{K}_{\mathrm{a}}$ radiation $(\lambda=0.71073 \AA)$ at $T=143 \mathrm{~K}$. All structures were refined to convergence against $\mathrm{F}^{2}$ using programs from the SHELX family ${ }^{46}$. Selected parameters are summarized in the Supplementary Tables S3-S5 and full details are given in Supplementary Data 1-8.

The Cambridge Crystallographic Data Center (www.ccdc.cam.ac.uk/conts/ retrieving.html) hosts the crystallographic data for these compounds. Deposition numbers: CCDC-778896 (cryptophane-A with $\mathrm{H}_{2} \mathrm{O}$ ); CCDC-778897 (cryptophane-A with Xe); CCDC-778902 (tripropargyl cryptophane 1, partially occupied); CCDC-778903 (tripropargyl cryptophane 1 with Xe); CCDC-778898 (triallyl cryptophane 2, collapsed); CCDC-778899 (triallyl cryptophane 2 with $\mathrm{CDCl}_{3}$ ); CCDC-778900 (triallyl cryptophane 2 with $\mathrm{MeOH}$ ); and CCDC-778901 (triallyl cryptophane 2 with Xe). ORTEP representations of eight reported structures are presented as Supplementary Figure S4a-h.

\section{References}

1. Koshland, D. E. Application of a theory of enzyme specificity to protein synthesis. Proc. Natl Acad. Sci. USA 44, 98-104 (1958).

2. Deutman, A. B. C. et al. Squaring cooperative binding circles. Proc. Natl Acad. Sci. USA 106, 10471-10476 (2009).

3. Pluth, M. D., Fiedler, D., Mugridge, J. S., Bergman, R. G. \& Raymond, K. N. Encapsulation and characterization of proton-bound amine homodimers in a water-soluble, self-assembled supramolecular host. Proc. Natl Acad. Sci. USA 106, 10438-10443 (2009).

4. Feringa, B. L. From molecules to molecular systems. Chimia 63, 254-256 (2009).

5. Kim, B. S. et al. Water soluble cucurbit[6] uril derivative as a potential Xe carrier for Xe-129 NMR-based biosensors. Chem. Commun. 2756-2758 (2008).

6. Brotin, T. \& Dutasta, J. P. Cryptophanes and their complexes-present and future. Chem. Rev. 109, 88-130 (2009).

7. Garel, L., Dutasta, J. P. \& Collet, A. Complexation of methane and chlorofluorocarbons by cryptophane-A in organic solution. Angew. Chem. Int. Ed. 32, 1169-1171 (1993).

8. Mecozzi, S. \& Rebek, J. The 55\% solution: a formula for molecular recognition in the liquid state. Chem. Eur. J. 4, 1016-1022 (1998).

9. Bartik, K., Luhmer, M., Dutasta, J. P., Collet, A. \& Reisse, J. Xe-129 and H-1 NMR study of the reversible trapping of xenon by cryptophane-A in organic solution. J. Am. Chem. Soc. 120, 784-791 (1998).

10. Cavagnat, D. et al. Raman microspectrometry as a new approach to the investigation of molecular recognition in solids: chloroform-cryptophane complexes. J. Phys. Chem. B 108, 5572-5581 (2004).

11. Canceill, J. et al. Structure and properties of the cryptophane- $\mathrm{CHCl}_{3}$ complex, a stable van der Waals molecule. Angew. Chem. Int. Ed. Engl. 28, 1246-1248 (1989).

12. Canceill, J., Cesario, M., Collet, A., Guilhem, J. \& Pascard, C. A new bis-cyclotribenzyl cavitand capable of selective inclusion of neutral molecules in solution-crystal-structure of its $\mathrm{CH}_{2} \mathrm{Cl}_{2}$ cavitate. J. Chem. Soc., Chem. Commun. 361-363 (1985).

13. Canceill, J. et al. Selective recognition of neutral molecules: ${ }^{1} \mathrm{H}$ NMR study of the complexation of $\mathrm{CH}_{2} \mathrm{Cl}_{2}$ and $\mathrm{CH}_{2} \mathrm{Br}_{2}$ by cryptophane- $\mathrm{D}$ in solution and crystal structure of its $\mathrm{CH}_{2} \mathrm{Cl}_{2}$ cavitate. J. Chem. Soc., Chem. Commun. 339-341 (1986).

14. Brouwer, E. B., Enright, G. D. \& Ripmeester, J. A. Solid state NMR and diffraction studies of $p$-tert-butylcalix [4] arene ${ }^{\star}$ nitrobenzene ${ }^{\star}$ xenon. J. Chem Soc., Chem. Commun. 119, 939-940 (1997).

15. Enright, G. D., Udachin, K. A., Moudrakovski, I. L. \& Ripmeester, J. A. Thermally programmable gas storage and release in single crystals of an organic van der Waals host. J. Am. Chem. Soc. 125, 9896-9897 (2003).

16. Miyahara, Y., Abe, K. \& Inazu, T. 'Molecular' molecular sieves: lid-free decamethylcucurbit[5] uril absorbs and desorbs gases selectively. Angew. Chem. Int. Ed. 41, 3020-3023 (2002).

17. Schiltz, M., Fourme, R. \& Prange, T. Use of noble gases xenon and krypton as heavy atoms in protein structure determination. Methods Enzymol. 374, 83-119 (2003).

18. Aaron, J. A. et al. Structure of a ${ }^{129} \mathrm{Xe}$-cryptophane biosensor complexed with human carbonic anhydrase II. J. Am. Chem. Soc. 130, 6942-6943 (2008).

19. Berthault, P., Huber, G. \& Desvaux, H. Biosensing using laser-polarized xenon NMR/MRI. Progr. Nucl. Magn. Reson. Spectrosc. 55, 35-60 (2009).

20. Taratula, O. \& Dmochowski, I. J. Functionalized Xe-129 contrast agents for magnetic resonance imaging. Curr. Opin. Chem. Biol. 14, 97-104 (2010).

21. Meldrum, T. et al. A xenon-based molecular sensor assembled on an MS2 viral capsid scaffold. J. Am. Chem. Soc. 132, 5936-5937 (2010).

22. Chambers, J. M. et al. Cryptophane xenon-129 nuclear magnetic resonance biosensors targeting human carbonic anhydrase. J. Am. Chem. Soc. 131, 563-569 (2009).

23. Seward, G. K., Wei, Q. \& Dmochowski, I. J. Peptide-mediated cellular uptake of cryptophane. Bioconjug. Chem. 19, 2129-2135 (2008).

24. Hill, P. A., Wei, Q., Troxler, T. \& Dmochowski, I. J. Substituent effects on xenon binding affinity and solution behavior of water-soluble cryptophanes. J. Am. Chem. Soc. 131, 3069-3077 (2009).

25. Bouchet, A., Brotin, T., Cavagnat, D. \& Buffeteau, T. Induced chiroptical changes of a water-soluble cryptophane by encapsulation of guest molecules and counterion effects. Chem. Eur. J. 16, 4507-4518 (2010).

26. Brotin, T., Cavagnat, D. \& Buffeteau, T. Conformational changes in cryptophane having C-1-symmetry studied by vibrational circular dichroism. J. Phys. Chem. A 112, 8464-8470 (2008)

27. Murakami, Y., Kikuchi, J., Hisaeda, Y. \& Hayashida, O. Artificial enzymes. Chem. Rev. 96, 721-758 (1996).

28. Rekharsky, M. V. \& Inoue, Y. Complexation thermodynamics of cyclodextrins. Chem. Rev. 98, 1875-1917 (1998).

29. Fan, Z. et al. Encapsulation of quinine by beta-cyclodextrin: excellent model for mimicking enzyme-substrate interactions. J. Org. Chem. 71, 1244-1246 (2006).

30. Bondi, A. Van der Waals volumes + radii. J. Phys. Chem. 68, 441-451 (1964).

31. Kirchhoff, P. D. et al. Structural fluctuations of a cryptophane host: a molecular dynamics simulation. J. Am. Chem. Soc. 118, 3237-3246 (1996).

32. Huber, G. et al. Water soluble cryptophanes showing unprecedented affinity for xenon: candidates as NMR-based biosensors. J. Am. Chem. Soc. 128, 6239-6246 (2006).

33. Mough, S. T., Goeltz, J. C. \& Holman, K. T. Isolation and structure of an 'imploded' cryptophane. Angew. Chem. Int. Ed. 43, 5631-5635 (2004).

34. Collet, A. Cyclotriveratrylenes and cryptophanes. Tetrahedron 43, 5725-5759 (1987). 
35. Brotin, T. \& Dutasta, J. P. Xe@cryptophane complexes with C-2 symmetry: synthesis and investigations by Xe-129 NMR of the consequences of the size of the host cavity for xenon encapsulation. Eur. J. Org. Chem. 973-984 (2003).

36. Fogarty, H. A. et al. A cryptophane core optimized for xenon encapsulation. J. Am. Chem. Soc. 129, 10332-10333 (2007).

37. Guex, N. \& Peitsch, M. C. SWISS-MODEL and the Swiss PdbViewer: an environment for comparative protein modeling. Electrophoresis 18, 2714-2723 (1997).

38. Duchamp, D. J. CrystMol, Version 2.1. (DandA Consulting LLC, 2004).

39. Huber, J. G. et al. NMR study of optically active monosubstituted cryptophanes and their interaction with xenon. J. Phys. Chem. A 108, 9608-9615 (2004).

40. Luhmer, M. et al. Study of xenon binding in cryptophane-A using laser-induced NMR polarization enhancement. J. Am. Chem. Soc. 121, 3502-3512 (1999).

41. Darzac, M., Brotin, T., Rousset-Arzel, L., Bouchu, D. \& Dutasta, J. P. Synthesis and application of cryptophanol hosts: Xe-129 NMR spectroscopy of a deuteriumlabeled (Xe) ${ }_{2} @$ bis-cryptophane complex. New J. Chem. 28, 502-512 (2004).

42. Desvaux, H., Huber, J. G., Brotin, T., Dutasta, J. P. \& Berthault, P. Magnetization transfer from laser-polarized xenon to protons with spin-diffusion quenching. ChemPhysChem 4, 384-387 (2003).

43. Brotin, T., Cavagnat, D., Dutasta, J. P. \& Buffeteau, T. Vibrational circular dichroism study of optically pure cryptophane-A. J. Am. Chem. Soc. 128, 5533-5540 (2006).

44. Hill, P. A. Synthesis of functionalized cryptophane-A derivatives and assessment of their xenon-binding properties for the construction of hyperpolarized xenon-129 biosensors. University of Pennsylvania, Philadelphia, PA (2008).

45. Hill, P. A., Wei, Q., Eckenhoff, R. G. \& Dmochowski, I. J. Thermodynamics of xenon binding to cryptophane in water and human plasma. J. Am. Chem. Soc. 129, 9262-9263 (2007)

46. Sheldrick, G. M. SHELXL-97. Acta. Cryst. A64, 112-122 (2008).

\section{Acknowledgments}

Support came from DOD (W81XWH-04-1-0657), NIH (CA110104, CA110104), NSF (CHE-0840438), a Camille and Henry Dreyfus Teacher-Scholar Award, and from the UPenn Chemistry Department.

\section{Author contributions}

O.T. wrote the manuscript, optimized many of the synthetic protocols, synthesized tripropargyl cryptophane and crystallized two of the reported cryptophane complexes. P.A.H. synthesized triallyl cryptophane, cryptophane-A and grew crystals that led to most of the reported cryptophane structures. N.S.K. helped to synthesize cryptophane precursors; P.J.C. performed X-ray crystal structure determinations and provided support with structural analysis; I.J.D. supervised this project and edited the manuscript.

\section{Additional information}

Supplementary Information accompanies this paper on http://www.nature.com/ naturecommunications

Competing financial interests: The authors declare no competing financial interests.

Reprints and permission information is available online at http://npg.nature.com/ reprintsandpermissions/

How to cite this article: Taratula, O. et al. Crystallographic observation of 'induced fit' in a cryptophane host-guest model system. Nat. Commun. 1:148 doi: 10.1038/ncomms1151 (2010)

License: This work is licensed under a Creative Commons Attribution-NonCommercialShare Alike 3.0 Unported License. To view a copy of this license, visit http:// creativecommons.org/licenses/by-nc-sa/3.0/ 